\title{
The Role of non-coding RNA in Cardiac Repair and Regeneration after Myocardial Infarction
}

Xi Chen, Mingming Yang, Pengfei Zuo, Rui Zhang, Zaixiao Tao, Genshan Ma*, Yongjun Li*

Department of Cardiology, Zhongda Hospital, School of Medicine, Southeast University 87 Dingjiaqiao, Nanjing, P.R.China 210009

*Corresponding Author: Yongjun Li, Genshan Ma, Department of Cardiology, Zhongda Hospital, School of Medicine, Southeast University 87 Dingjiaqiao, Nanjing, P.R.China 210009

Received Date: February 02, 2020; Accepted Date: February 25, 2021; Published Date: March 02,2021

Citation: Xi Chen., Mingming Yang., Pengfei Zuo., Rui Zhang., Zaixiao Tao., Genshan Ma., Yongjun Li., (2021) The role of non-coding RNA in Cardiac Repair and Regeneration after Myocardial Infarction. J. Clinical Cardiology and Cardiovascular Interventions, 4(6); Doi:10.31579/2641$0419 / 136$

Copyright: ( 2021 Yongjun Li, Genshan Ma, This is an open-access article distributed under the terms of the Creative Commons Attribution License, which permits unrestricted use, distribution, and reproduction in any medium, provided the original author and source are credited.

\begin{abstract}
Myocardial infarction (MI), one of the cardiovascular diseases (CVDs) with high incidence and mortality rate, seriously endangers human health. The poor ways of fully repairing and regenerating the infarcted myocardium may have an impact on people's life quality, therefore scientists have devoted continuously to exploring the way of myocardial repair after MI so as to strive for a better prognosis of these patients. In recent years, non-coding RNAs (ncRNAs) have been identified and become one of the exciting fields of research in the development of CVDs. In a wide range of areas, more and more research has found that ncRNAs play important roles in myocardial repair. This review mainly introduces some strategies for myocardial repair and the role or mechanism of microRNA (miRNA), long non-coding RNA (lncRNA), circular RNA (circRNA) and circRNA/IncRNA-miRNA-mRNA regulatory axis in the repair of myocardial tissue after MI, in order to build a better understanding and find new therapeutic targets for MI.
\end{abstract}

Keyword: long non-coding RNAs; myocardial infarction; cardiac repair

\section{Abbreviations:}

BM-MSCs : bone marrow derived mesenchymal stem cells

CVDs circRNA

: cardiovascular diseases

Col I, III

: circular RNA

: collagen I, III
CTGF

CXCR4

DNMT

ERK1/2

EGFL7

HIF-1a

IncRNA

MAPK

MI

miRNA, miR

miPSC

mTOR

ncRNAs

PI3K

: connective tissue growth factor

: C-X-C chemokine receptor type 4

: DNA (cytosine-5-)-methyltransferase

: extracellular signal-regulated kinase $1 / 2$

: epidermal growth factor-like domain 7

: hypoxia inducible factor $1 \alpha$

: long non-coding RNA

: mitogen-activated protein kinase

: myocardial infarction

ISSN: 2641-0419

$\begin{array}{ll}\text { PDGF } & \text { : Platelet derived growth factor } \\ \text { PCFL } & \text { : Primary cutaneous follicular lymphoma } \\ \text { RISC } & : \text { miRNA-induced silencing complex } \\ \text { TGF- } \beta & : \text { transforming growth factor } \beta \\ \text { 3' UTR } & : \text { 3' untranslated region } \\ \text { VEGF-A } & : \text { vascular endothelial growth factor-A }\end{array}$

\section{Introduction}

Myocardial infarction (MI), a cardiovascular disease with high morbidity and mortality in the world, is caused by blockage of coronary arteries, leading to apoptosis or necrosis of cardiomyocytes induced by continuous ischemia and hypoxia1. Evidence has shown that many cardiomyocytes are lost when MI occurs. Fibrous repair, also called scar repair is thought to be the main way of repair after MI because cardiomyocytes regeneration capacity is limited [2]. However, a large amount of scar tissue seriously affects myocardial systolic and diastolic function, which greatly increases the incidence of adverse events followed by MI [3]. Therefore, finding more ideal ways and strategies for myocardial repair after MI has become the research hotspot and difficulty of many scientists.

At present, it is unanimously believed that the most ideal way to repair damaged myocardium is to promote the regeneration of myocardium as a substitute for apoptotic cardiomyocytes 4 . In addition, studies have also focused on promoting angiogenesis in the infarct area5, inhibiting myocardial cell apoptosis [6], inflammatory response [7], excessive fiber 
and collagen deposition [8]. Although scientists have been constantly exploring, so far it is still at the level of simple animal or cell experiments, and more molecular mechanisms and clinical treatments need to be explored.

It is reported that about $2 \%$ of the human genome is composed of proteincoding regions. Most transcripts are non-coding RNAs (ncRNAs), mainly including microRNA (miRNA, miR), long non-coding RNA (lncRNA), and circular RNA (circRNA) [9]. The ncRNAs have been confirmed to play important roles in occurrence and development of various diseases through different molecular mechanisms10. MiRNA, together with some proteins, forms the miRNA-induced silencing complex (RISC), which acts on the 3' untranslated region (3' UTR) of the target mRNA and then degrade it or inhibit it's translation. Overall miRNA may participate in a variety of biology functions and control various cellular processes by negatively regulating gene expression11. Different from miRNA, lncRNA and circRNA mainly act as a "sponge" or endogenous competitor molecule of miRNA to affect the miRNA's function expression which finally regulate the occurrence and development of various human diseases [12]. In recent years, it has been reported that miRNA, IncRNA and circ-RNA play significant roles in repairing damaged myocardium [13], so this paper mainly reviews the role and mechanism of lncRNA, miRNA, circRNA separately and the regulatory networks of lncRNA/circRNA-miRNA-mRNA in tissue repair after MI for the purpose of providing some new ideas and targets for the treatment of MI (figure1).

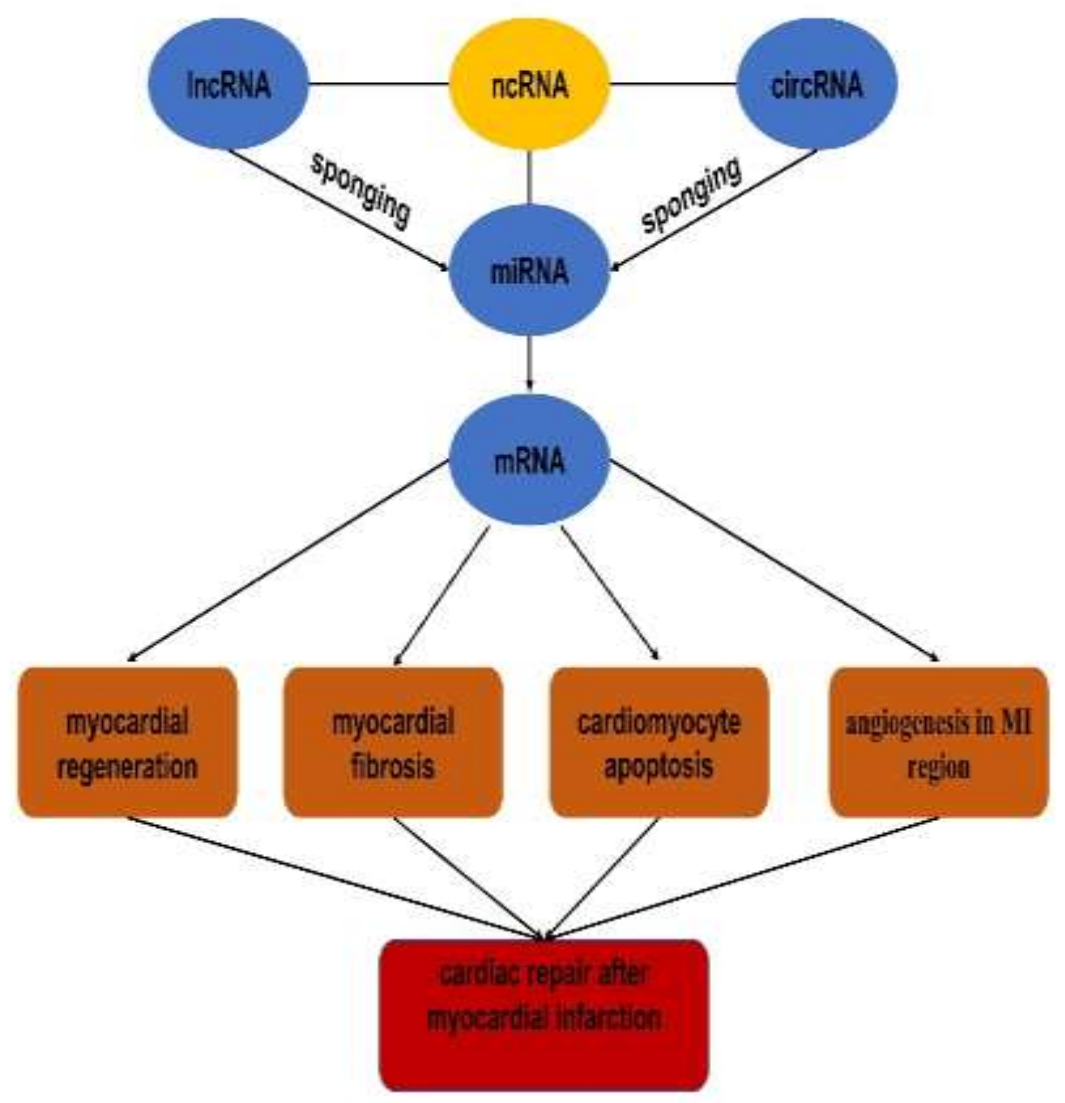

Figure1 circRNA/IncRNA-miRNA-mRNA regulatory axis in cardiac repair after $M I$

\section{NcRNAs in myocardial regeneration}

The loss of a large number of cardiomyocytes when someone have a MI seriously affects the prognosis. Although scientists have been searching for better therapies to repair injured myocardial tissue, to date regenerate cardiomyocytes is recognized as the most ideal treatment method for repair of damaged myocardium [4], for example transplanting stem cell to induce cardiomyogenic differentiation, activating and inducing resident cardiac progenitor cells or cardiomyocytes to re-enter the cell proliferation cycle [14-16]. And increasing evidence indicate that the activating of cardiomyocytes proliferation and the survival rate of stem cells transplanted into the infarct area are controlled by the microRNA network $[4,13]$.

Discussion on whether the cardiomyocytes could regenerate has always been a contentious issue. The more accepted view is that heart of the adult mammalian, as a terminal differentiation of organs, is unable to regenerate after myocardial injury [2]. However, in recent years, some studies have pointed out that the heart of newborn mammals maintain a short-term regenerative capacity after birth, and then this ability gradually get lost $[17,18]$. Therefore, reactivation of cardiac cell proliferation is a key strategy for inducing cardiac regeneration in adults. Yang et al. stated that the level of miR-34a in the heart of mice after birth was low, and rose to adult levels soon, Antagonist of miR-34a enhanced endogenous repair and regeneration following MI partly by regulating cell cycle factors and apoptotic factors, including Bcl2, Cyclin D1 and Sirt1 [19]. MiR-21 has been reported to break through the G1/S phase restriction point and enter $\mathrm{S}$ phase to promote cardiac stem cell proliferation through the activation of phosphoinositide 3 kinase (PI3K) /AKT signaling pathway [20]. In early postnatal mice, myocardium-specific overexpression of miR-128 inhibited the proliferation of cardiomyocyte. In contrast, knocking out miR-128 can reactivate cardiomyocyte proliferation and regeneration in adult mice, which is partly achieved by targeting Suz12 in the heart to regulate cell cycle-related genes [21]. Pandey et al. discovered the expression of miR-199a could be regulated by transfected miR-1825 in animal model, which in turn downregulates the expression of $\mathrm{p} 16, \mathrm{Rb} 1$ 
and Meis2 to induce the proliferation of cardiomyocytes around the infarct area [22]. The miR302-367 cluster has been observed to have huge potential in promoting the proliferation of embryonic and postnatal cardiomyocytes, and the mechanism maybe lies in regulating targeting multiple kinases via Hippo signal transduction pathway, then Wang's group innovatively injected hyaluronic acid gel wrapped miR-302 mimics to myocardial infarction site of mouse, then led to cardiomyocyte proliferation in the marginal area [23]. Similarly, Pierluigi group found that administration of lipid formulations of hsa-miR-199a-3p and hsamiR-590-3p immediately after MI in mice resulted in marked reduction of infarct size and persistent recovery of cardiac function [24]. In recent years, some scientists have made innovative use of bioengineering to deliver target molecules into specific cells in the heart, so as to exert their best effect as well as pushed miRNA therapeutics a step forward toward clinical application. But these techniques are still immature and remain some safety issues, more experiments are needed to improve them.

It has been widely accepted that lncRNA and circRNA can regulate the process of cell proliferation and differentiation. IncRNA NR_045363, a highly conserved lncRNA, is mainly expressed in cardiomyocytes. Wang et al. noticed that over-expression of NR_045363 could strengthen DNA synthesis and cell division of neonatal cardiomyocytes cultured in vitro, The mechanism may be that NR_045363 interacts with miR-216a, thereby regulating JAK2-STAT3 pathway to promote cardiomyocyte proliferation [25]. Chen et al. reported that lnc RNA ecrr enhanced the proliferation of cardiomyocyte after birth and the recovery of function following MI through the extracellular signal-regulated kinase $1 / 2$ (ERK1/2) dependent mechanism [26]. Cai et al. claimed that LncDACH1 is gradually upward in the heart after birth, while knocked out LncDACH1 and silenced adenovirus-mediated endogenous LncDACH1 in vivo conditional, the proliferative potential of cardiac myocytes was activated in both young and adult mice, further mechanism research revealed that LncDACH1 induced heart regeneration after birth and ischemic heart by regulating PP1A/YAP1 signal [27]. Yan et al. found that the lncRNA-RMRP/miR-214-5p axis regulated the expression levels of Ki67, cyclinD1 and CDK4 by directly targeting p53, ultimately promoted the proliferation of $\mathrm{H} 9 \mathrm{C} 2$ cells induced by hypoxia [28]. Contrary to the proliferative effect of IncRNA-RMRP, human-derived IncRNA CRRL is a new negative regulator of myocardial cell regeneration after $\mathrm{MI}$. CRRL suppressed myocardial regeneration by acting as an endogenous miR-199a-3p sponge [29]. LncRNA CPR, known as cardiomyocyte proliferation regulator, has been verified in animal experiments to interacted directly with DNMT3A and MCM3 promoter $\mathrm{CpG}$ island methylation, restrained MCM3 expression and involved in Inhibition of cardiomyocytes proliferation [30]. Emerging evidence suggested that circRNAs may play fundamental roles in promoting or inhibiting cardiac regeneration. For instance, circRNA Nfix (circNfix) is regulated by a super-enhancer and overexpressed in adult hearts of humans, rats and mice. In vitro study, the expression of circNfix did cut down in circNfix knockout cell lines from HL-1 mouse cardiomyocytes, meanwhile it was interesting that proliferation of cardiomyocytes significantly increased. Subsequently, in animal model of MI, the circNfix was down-regulated by injecting AAV9-shcircnfix or AAV9-shNC in the area around the infarction, as expected, 14 days after MI, the down-regulation of circNfix induced cardiomyocyte proliferation in the marginal zone of infarction by $2 \%-4 \%$, and the mechanism by which circNfix controlled cardiomyocyte proliferation may be to promote Y-box binding protein 1 ubiquitin degradation by acting as a miR-214 sponge [31], the result showed the great potential of circRNA to promote cardiomyocyte regeneration and effective cardiac repair, But at present, there are not many related researches, and a lot of exploration is needed.

Stem cell therapy has always been a research hotspot in the field of MI. More and more scholars are devoted to repairing ischemia-induced myocardial injury with stem cells [32]. It has been confirmed that stem cell transplantation can differentiate into cardiomyocytes and promote the repair of injured myocardium. The mechanism may be related to ncRNAs. Recently exploitation of miRNA in stem cells for post-MI has to be attempted. Some scholars have begun to artificially interfere with the content of certain RNAs in stem cells, which may more effectively promote the differentiation of stem cells into cardiomyocytes [33,34]. For example, in vitro experiments, Yang et al. mentioned that the conditioned medium produced by mesenchymal stem cells (MSCs) had the ability to promote the proliferation of cardiomyocytes, which is enhanced after the suppression of miR-21. At the same time, an in vivo study confirmed that after inhibition of miR-21 expression, the ability of MSCs transplanted to the infarcted site for treating MI is improved [35]. A similar study have found that overexpression of miR-129 may promote the differentiation of bone marrow derived mesenchymal stem cells(BM-MSCs) into myocardial-like cells by activating the Wnt signaling pathway, while miR-148a induced MSCs to differentiate into myocardium through targeted regulation of DNA (cytosine-5-)-methyltransferase 1(DNMT1), Chen et al. conducted genetic studies using miR-17-92 gene knockout and transgenic mice, as well as in vitro cell culture, which results showed that the members of the 17-92 cluster are necessary to induce cardiomyocyte proliferation [36]. Transplantation of miR-1 transfected MSCs raised the survival rate of transplanted cells and the rate of cardiogenic differentiation, which is conducive to the repair of infarct injury [37]. In addition, it has been reported that miR-1 and miR-133 are highly expressed in myocardial tissue and participate in that process of myocardial formation and development in embryonic stage, whereas the separate upregulation of miR-1 or miR-133 have no obvious promoting effect in the process of differentiation into cardiomyocytes induced by mouse-induced Pluripotent stem cell (miPSC). Only when overexpression of miR-1 and miR-133 at the same time, can they synergistically promote the differentiation of miPSC into cardiomyocytes in vitro, this effect is mainly achieved by increasing the phosphorylation level of in ERK1/2/ mitogen-activated protein kinase (MAPK) pathway [38], which suggests that there may be some synergistic effect between miRNAs. An in vitro experiment found LncRNA Bravehearl transfection can effectively promote the differentiation of BM-MSCs into cardiomyocyte-like cells. However, it is reported that the efficacy of stem cell transplantation is still not ideal. One of the important factors is the low survival rate and differentiation efficiency of stem cells in the local infarct microenvironment in vivo, and their ability to differentiate into cardiomyocytes is extremely limited, so exploring to promote the survival and differentiation of stem cells in the infarct microenvironment efficiency has become a difficult problem to be solved.

In addition to regulating myocardial differentiation, miR-133 has also been reported to inhibit the apoptosis of MSCs under hypoxic conditions [39]. Dakhlallah et al. found that transfection of miR-133a mimics can enhance the viability of MSCs in the heart of MI by reducing the mRNA expression of Apaf-1 and caspase-940. MiR-23a has been stated to protect BM-MSCs from apoptosis under hypoxic conditions by regulating caspase-741. An in vitro study have shown that the miR-21 can reduce apoptosis, promote proliferation and differentiation of MSCs [35], Garikipati et al. emphasized that the negative regulation of IL-10 on miR375 can improve the survival rate and function of bone marrow-derived progenitor cells in ischemic myocardium, and improve the repair after MI [42]. Another animal study described that transplantation of MSCs with overexpressing miR-1 into the infarcted area can promote cardiogenic differentiation by improving the survival rate of transplanted cells [37], although above studies have shown that ncRNAs do have a certain effect on improving the microenvironment of myocardial infarction area and the survival rate of stem cells, but it is far from enough. With the development of stem cell therapy research, scholars have gradually found that some transplanted stem cells improve heart function mainly through their paracrine function, there are a large number of miRNAs carried by 
paracrine exosomes, can be taken up by surrounding cells and participate in the repair of damaged myocardium[43]. A new type of cell-free therapy based on exosomes secreted by stem cells can be considered as a safe and effective alternative to stem cell therapies for cardiovascular disease [44] (Table 1).

\begin{tabular}{|c|c|c|c|c|}
\hline NcRNA & $\begin{array}{l}\text { Up/down } \\
\text { regulate }\end{array}$ & $\begin{array}{lll}\begin{array}{l}\text { Targets } \\
\text { pathway }\end{array} & \text { and/or } & \text { signal } \\
\end{array}$ & Function & Reference \\
\hline miR-34a & $\downarrow$ & Bcl2, Cyclin D1, Sirt1 & enhance $\mathrm{CM}$ regeneration & [19] \\
\hline miR-21 & $\uparrow$ & PI3K/AKT signal pathway & $\begin{array}{l}\text { break through the G1/S phase restriction point and enter } \\
\text { S phase }\end{array}$ & {$[20]$} \\
\hline miR-128 & $\downarrow$ & Suz12 & $\begin{array}{l}\text { reactivate } \mathrm{CM} \text { proliferation and regeneration in adult } \\
\text { mice }\end{array}$ & [21] \\
\hline miR-1825 & $\uparrow$ & $\begin{array}{l}\text { miR-199a, p16, Rb1 and } \\
\text { Meis2 }\end{array}$ & induce the proliferation of CM around the infarct area & [22] \\
\hline miR-302 & $\uparrow$ & Hippo signal pathway & promote the proliferation of embryonic and postnatal $\mathrm{CM}$ & [23] \\
\hline lnc NR_045363 & $\uparrow$ & $\begin{array}{l}\text { miR-216a, JAK2-STAT3 } \\
\text { signal pathway }\end{array}$ & $\begin{array}{l}\text { strengthen DNA synthesis and cell division of neonatal } \\
\text { CM cultured in vitro }\end{array}$ & {$[25]$} \\
\hline lnc ecrr & $\uparrow$ & ERK1/2 & enhance the proliferation of CM after birth & [26] \\
\hline lnc DACH1 & $\downarrow$ & PP1A/YAP1 signal pathway & activate the proliferative potential of $\mathrm{CM}$ in mice & [27] \\
\hline lnc-RMRP & $\uparrow$ & $\begin{array}{l}\text { miR-214-5p, Ki67, } \\
\text { cyclinD1, CDK4, p53 }\end{array}$ & promote the proliferation of $\mathrm{H} 9 \mathrm{C} 2$ cells & [28] \\
\hline lnc CRRL & $\uparrow$ & miR-199a-3p & suppress myocardial regeneration & [29] \\
\hline $\operatorname{lnc} \mathrm{CPR}$ & $\uparrow$ & DNMT3A, MCM3 & inhibit $\mathrm{CM}$ proliferation & [30] \\
\hline circ Nfix & $\downarrow$ & miR-214 & $\begin{array}{l}\text { induce CM proliferation in the marginal zone of } \\
\text { infarction }\end{array}$ & {$[31]$} \\
\hline miR-17-92 & $\uparrow$ & & induce cardiomyocyte proliferation in vitro cell culture & {$[36]$} \\
\hline miR-1, miR-133 & $\uparrow$ & $\begin{array}{l}\text { ERK1/2/MAPK signal } \\
\text { pathway }\end{array}$ & $\begin{array}{l}\text { synergistically promote the differentiation of miPSC into } \\
\mathrm{CM} \text { in vitro }\end{array}$ & [38] \\
\hline miR-133a & $\uparrow$ & Apaf-1, caspase- 9 & enhance the viability of MSCs & [40] \\
\hline miR-23a & $\uparrow$ & caspase-7 & protect transplanted BM-MSCs from apoptosis & [41] \\
\hline miR-375 & $\downarrow$ & & $\begin{array}{l}\text { improve the survival rate and function of bone marrow- } \\
\text { derived progenitor cells }\end{array}$ & {$[42]$} \\
\hline
\end{tabular}

Abbreviations: miR microRNA, lnc long non-coding RNA, circ circular RNA, BM-MSCs bone marrow derived mesenchymal stem cells, MSCs mesenchymal stem cells, CM cardiomyocytes, miPSC mouse-induced Pluripotent stem cell

\section{Table1 NcRNAs in myocardial regeneration}

\section{NcRNAs in regulation of myocardial fibrosis}

It is well known that cardiomyocytes cannot be completely regenerated following MI. The main repair method is scar repair, which is manifested as myocardial fibrosis and specifically includes the proliferation of myocardial fibroblasts as well as excessive deposition of extracellular matrix [45]. In the early post-MI period, fibrosis in the infarcted area is a favorable pathologic repair process, conducive to healing of scar tissue and prevention of ventricular rupture. However, with the extension of infarction time, fibrosis in the peripheral area of the infarction will seriously affect myocardial contractility and diastolic function, which is not beneficial to repair of cardiac function [46]. More and more scholars have proposed reasonable regulation of myocardial fibrosis after infarction and inhibition of late myocardial fibrosis is a valuable strategy for myocardial tissue repair, plenty of evidence indicate that miRNAs are a new type of myocardial fibrosis regulator that can regulate the proliferation activities of cardiac fibroblasts [47].

Some miRNAs have been shown to inhibit myocardial fibrosis, for example, miR-126 may control the proliferation and differentiation of myocardial fibroblasts by raising the expression of epidermal growth factor-like domain 7(EGFL7) and activating the AKT/ERK signaling pathway [48], while miR-29a targets vascular endothelial growth factorA (VEGF-A)/MAPK signaling pathway inhibited myocardial fibrosis
[49]. Platelet derived growth factor (PDGF) is a low molecular weight cytokinin that stimulates the growth of connective tissue and other tissue cells [50]. PGDFR- $\beta$ was confirmed to be a target molecule of miR-9, overexpression of miR-9 disturbed myocardial fibrosis by targeting PDGFR- $\beta$. Previous studies have shown that the transforming growth factor $\beta$ (TGF- $\beta$ )/Smads signal transduction pathway plays a significant role in the process of regulating myocardial fibrosis. After the onset of myocardial infarction, the content of TGF- $\beta 1$ in myocardial tissue increased, and the signal transduction pathway of TGF- $\beta /$ Smads was activated rapidly, which promoted the expression of downstream genes, mainly including type I and type III collagen(Col I , Col III), resulting in continuous deposition of extracellular matrix collagen [51]. MiR-214 [52] and miR-101a [53] have been reported to directly down-regulate the expression of TGF- $\beta$ RI in cardiac fibroblasts, thereby inhibiting the TGF$\beta$ signaling pathway and exerting an anti-fibrotic effect. Recently, an interesting study concluded that controlling intermittent aerobic exercise can help repair myocardial tissue and improve cardiac function after MI. In that second week after successful preparation of the AMI rat model, the mice began sustained aerobic exercise, and as a result, it was observe that the progression of myocardial fibrosis and scar formation was delayed, further studies have revealed that aerobic exercise induced high expression of miR-29a and miR-101 and regulates the level of fibrotic factors including TGF- $\beta$, Fos, Smad2/3, Col I and Col III, thereby 
inhibiting the deposition of myocardial interstitial collagen [54]. Chen et al. transfected the vector carrying the miR-30a gene into the heart of AMI model rats, and after 4 weeks it was found that highly expressed miR-30a directly binds to the 3'-UTR of connective tissue growth factor (CTGF) after four weeks. CTGF is a mitogen secreted by vascular endothelial cells [55]. In vitro experiments have shown that CTGF could stimulate the proliferation of myocardial fibroblasts and mediate tissues repair under pathological conditions. miR-30a inhibited the expression of CTGF post MI, then reduced the formation of myocardial collagen and inhibited myocardial fibrosis [56]. He et al. knocked out the miR-144 gene and established an AMI rat model, It was found that the deletion of miR-144 may increase collagen cross-linking, and reduce the incidence of early myocardial rupture after myocardial infarction via the Zeb1/LOX1 signal axis [57], but it is unclear whether it has a long-term effect. MiR-1 has been shown to negatively regulate fibroblast proliferation. MiR-1 has been reported to partially inhibit fibroblast proliferation mediated through targeted inhibition of cyclin D2 and CDK6 [58].

In addition, some miRNAs have been confirmed to promote myocardial fibrosis. Among them, miR-328 could promote the production of collagen in the marginal zone of infarction by targeting TGF- $\beta$ R3 [59]. It was reported that overexpression of $\mathrm{miR}-7 \mathrm{a} / \mathrm{b}$ reduced the size of myocardial fibrosis around the infarct area by decreasing the expression of $\mathrm{Sp} 1$ and Col I [60]. miR-21 has been confirmed to be mainly present in myocardial fibroblasts and is closely related to myocardial fibrosis after infarction. There are some scholars support the view that miR-21 could regulate the proliferation and differentiation process of fibroblasts, mainly through TGF- $\beta$ /Smads signal transduction pathway. Liang et al. found that TGF$\beta 1$ and miR-21 were up-regulated, whereas TGF- $\beta$ R3 was downregulated in the border zone of mouse hearts in response to MI. Raising the expression of miR-21 could increase the content of collagen, at least in part by down-regulate TGF- $\beta \mathrm{R} 3$, on the contrary, the expression of TGF- $\beta R 3$ can inhibit the expression of miR-21 in fibroblasts, reduce the production of collagen, can also make the TGF- $\beta 1$ channel inactivation by lowering the expression of TGF- $\beta 1$ and $\mathrm{p}-\mathrm{Smad} 3$. Such a reciprocal loop between miR-21 and TGF- $\beta$ R3 in myocardial fibrosis is worth exploring further [61]. However the specific regulatory role of miR-21 in myocardial fibrosis, the current research results are inconsistent, Chen et al. thought that inhibiting the expression of miR-21 instead promotes the activation of fibroblasts [62]. The specific regulatory role of miRNA-21 in myocardial fibrosis remains somewhat controversial, which may be related to the expression of miR-21 in different periods of MI and multiple regulatory mechanisms. However, it is worth noting that whether the positive or negative action of miRNA, including miR-21, reasonable regulation of miRNA expression levels and promotion of mutual cooperation or antagonism among miRNAs can regulate fibroblast proliferation and move toward a favorable pathological repair process to improve the prognosis of patients with MI.

With the continuous development of studies, the regulatory levels of circRNA and lncRNA are believed to be closely related to myocardial fibrosis. CircRNA and lncRNA have been proved to be generally acted as miRNA sponges, and play a regulatory role in circRNA-miRNA or lncRNA-miRNA modes. A recent study demonstrated that circ_LAS1L inhibited its activity by adsorbing miR-125b, thereby promoting SFRP5 expression and inhibiting collagen deposition [62]. MIAT, a kind of lncRNA, known as myocardial infarction-related transcript, was recently indicated that could promote fibrosis and regulate myocardial fibrosis after infarction which specifically promotes fibroblast proliferation and collagen deposition by down-regulating the expression of miR-24 [64]. Primary cutaneous follicular lymphoma (PCFL) has been proved to be a new type of profibrotic lncRNA, overexpression of PCFL can aggravate myocardial fibrosis after MI, and heterozygous knockout of PCFL can reverse this change, further mechanism exploration found that PCFL has the function of miR-378 sponge, which alleviated the inhibition of miR378 on GRB2 [65]. Zhang et al. established the rat model of AMI by subcutaneous injection of isoproterenol, and observed the effect of lncRNA growth arrest specificity 5 (GAS5) on AMI rats, which showed that the cardiac function of the siRNA GAS5 group was significantly improved when compared with the model group, the myocardial tissue pathological damage was reduced, and the myocardial cell apoptosis rate was reduced. And they supposed underlying mechanism may be related to the up-regulation of miR-21 and the regulation of serum levels of MMP-2 and MMP-9 after MI [66]. IncRNA H19 has been thought to be an extracellular matrix regulator[67]. H19 knockout has been shown to enhanced the anti-fibrotic effect of miR-455, decreased the expression of $\mathrm{CTGF}$, and further reduce the synthesis of fibrosis-related proteins $(\mathrm{Col}$ I , Col III and $\alpha$-SMA) [68]. The above research indicated that circRNA and lncRNA play important roles in myocardial fibrosis, and generally regulate the expression level of miRNA in the form of miRNA sponge to regulate the proliferation of fibroblasts and other activities (Table 2).

\begin{tabular}{|c|c|c|c|c|}
\hline NcRNA & $\begin{array}{l}\text { Up/down } \\
\text { regulate }\end{array}$ & $\begin{array}{l}\text { Targets and/or signal } \\
\text { pathway }\end{array}$ & Function & Reference \\
\hline miR-126 & $\uparrow$ & $\begin{array}{l}\text { EGFL7, AKT/ERK } \\
\text { signal pathway }\end{array}$ & $\begin{array}{l}\text { control the proliferation and differentiation } \\
\text { of myocardial fibroblasts }\end{array}$ & [48] \\
\hline miR-29a & $\uparrow$ & $\begin{array}{l}\text { VEGF-A/MAPK } \\
\text { signal pathway }\end{array}$ & inhibit myocardial fibrosis & [49] \\
\hline miR-9 & $\uparrow$ & $\begin{array}{l}\text { TGF- } \beta / \text { Smads signal } \\
\text { pathway }\end{array}$ & $\begin{array}{l}\text { inhibit deposition of extracellular matrix } \\
\text { collagen }\end{array}$ & {$[51]$} \\
\hline $\begin{array}{l}\text { miR-214, } \\
\text { miR-101a }\end{array}$ & $\uparrow$ & TGF- $\beta$ RI & exert an anti-fibrotic effect & [52] [53] \\
\hline $\begin{array}{l}\operatorname{miR}-29 a \\
\operatorname{miR}-101\end{array}$ & $\uparrow$ & $\begin{array}{l}\text { TGF- } \beta, \text { Fos, Smad } 2 / 3, \\
\text { Col I and Col III }\end{array}$ & $\begin{array}{l}\text { inhibit the deposition of myocardial } \\
\text { interstitial collagen }\end{array}$ & {$[54]$} \\
\hline miR-30a & $\uparrow$ & CTGF & $\begin{array}{l}\text { reduce the formation of myocardial collagen } \\
\text { and inhibit myocardial fibrosis }\end{array}$ & {$[56]$} \\
\hline miR-144 & $\downarrow$ & $\begin{array}{l}\text { Zeb1/LOX1 signal } \\
\text { pathway }\end{array}$ & $\begin{array}{l}\text { increase collagen cross-linking, and reduce } \\
\text { the incidence of early myocardial rupture } \\
\text { after myocardial infarction }\end{array}$ & [57] \\
\hline miR-1 & $\uparrow$ & cyclin D2 and CDK6 & inhibit fibroblast proliferation & {$[58]$} \\
\hline miR-328 & $\uparrow$ & TGF- $\beta$ R3 & $\begin{array}{l}\text { promote the production of collagen in the } \\
\text { marginal zone of infarction }\end{array}$ & [59] \\
\hline
\end{tabular}




\begin{tabular}{|c|c|c|c|c|}
\hline $\mathrm{miR}-7 \mathrm{a} / \mathrm{b}$ & $\uparrow$ & Sp1 and Col I & $\begin{array}{l}\text { reduce the size of myocardial fibrosis around } \\
\text { the infarct area }\end{array}$ & [60] \\
\hline miR-21 & $\uparrow \uparrow$ & $\begin{array}{l}\text { TGF- } \beta / \text { Smads signal } \\
\text { pathway }\end{array}$ & increase the content of collagen & [61] \\
\hline miR-21 & $\downarrow$ & & promote the activation of fibroblasts & [63] \\
\hline circ_LAS1L & $\uparrow$ & miR-125b, SFRP5 & inhibit collagen deposition & [64] \\
\hline $\operatorname{lnc}$ MIAT & $\uparrow$ & $\operatorname{miR}-24$ & $\begin{array}{l}\text { promote fibroblast proliferation and } \\
\text { collagen deposition }\end{array}$ & [65] \\
\hline lnc PCFL & $\uparrow$ & $\operatorname{miR}-378$ & aggravate myocardial fibrosis after MI, & [65] \\
\hline lnc GAS5 & $\downarrow$ & $\begin{array}{l}\text { miR-21, } \\
\text { MMP-9 }\end{array}$ & reduce pathological damage & [66] \\
\hline $\operatorname{lnc} \mathrm{H} 19$ & $\downarrow$ & $\begin{array}{l}\text { miR-455, Col I, Col } \\
\text { III and } \alpha \text {-SMA }\end{array}$ & enhance the anti-fibrotic effect & [68] \\
\hline
\end{tabular}

Abbreviations: miR microRNA, lnc long non-coding RNA, circ circular RNA, MI myocardial infarction

Table2 NcRNAs in regulation of myocardial fibrosis

\section{NcRNAs in inhibition of cardiomyocyte apoptosis}

Cardiomyocyte apoptosis is the most typical and intuitive pathological response after MI. When MI occurs, there is a large amount of cardiomyocyte necrosis in the area of infarct and a large number of cardiomyocytes in the marginal zone of the infarct undergo apoptosis6. The proliferation of cardiomyocytes was limited and could not regenerate completely to replace apoptotic cardiomyocytes, which seriously damaged the cardiac function of patients with AMI [69]. Therefore, inhibition of cardiomyocyte apoptosis induced by hypoxia is one of the therapeutic strategies for MI.

Increasing number studies have shown that various miRNAs can participate in the regulation mechanism of cardiomyocytes apoptosis. It has been reported that Inhibition of miR-363 could protect cardiomyocytes against hypoxia-induced apoptosis by promoting expression of Notch1 and activating it's signaling pathway [70]. Inhibiting the expression of miR-155 also cut down the rate of cardiomyocytes apoptosis in mice with MI by targeting RNA-binding protein quaking (QKI), significantly narrowed infarction size [71]. Yao et al found that overexpression of miR-182-5p could inhibit the content of PTEN and enhance the AKT/GSK-3 signaling pathway to show the antiapoptotic effect in cell experiments [72]. In vivo and vitro studies have shown that the over-expression of miR-30 family members reduced the expression of cysteine c-lyase (CSE) and the production of $\mathrm{H} 2 \mathrm{~S}$, in turn aggravated the myocardial cell injury induced by hypoxia. In contrast, the down-regulation of the full miR-30 family protected cardiomyocytes from hypoxic damage [73]. Feng et al. found that C-X-C chemokine receptor type 4 (CXCR4) can be negative regulated by miR-210. Downregulation of miR-210 mediated the expression of CXCR4, and then activated Smad and mammalian target of rapamycin (mTOR) signaling pathways to mitigate hypoxia-induced $\mathrm{H} 9 \mathrm{C} 2$ cell damage, which provided a new regulatory axis for the expression of miR-210 after MI [74].

In studying the role of miRNA in the early stage of AMI, Ceviker et al. compared the miRNA expression profile in 6 hours after MI with the noninfarct area in rats. The results showed that the expression of miR-21 was significantly down-regulated in the infarct area and up-regulated in the marginal area of the infarct [75]. Subsequently Wang et al. found that increased expression of miR-21 could inactivated the PTEN/AKT/FOXO3a signaling pathway and inhibit TNF-a-induced cardiomyocyte apoptosis in neonatal rats [76]. Liu et al. found a positive feedback relationship between Hypoxia inducible factor $1 \alpha(\mathrm{HIF}-1 \alpha)$ and miR-21 by regulating the PTEN/AKT signaling pathway. HIF- $1 \alpha$-miR-
21 feedback plays an important role in inhibiting apoptosis during hypoxia. It is also reported that miR-1 has the potential to protect cardiomyocytes [77]. Xue et al. innovatively encapsulated miR-1 inhibitors into a dendritic nanocarrier coupled with myocardial-targeted at 1 peptide, targeted injection into the myocardial infarction area, and found that the number of apoptotic cells in the dead marginal area was significantly reduced which shows the prospect of early treatment of MI [78]. $\mathrm{Xu}$ et al. further found that miR-1 and miR-21 have a synergistic protective effect on hypoxia-induced cardiomyocyte apoptosis, which was the advance on single miRNA study and needed more research [79].

Autophagy is an evolutionarily conserved process of intracellular degradation. It maintains intracellular homeostasis by removing damaged proteins and organelles to produce ATP. Autophagy can protect cell viability and reduce the infarct size following MI, subsequently, alleviate left ventricular remodeling under mild ischemia [80]. Yan et al. revealed that miR-145 induced autophagy via the AKT3/mTOR signaling pathway to inhibit myocardial infarction-induced apoptosis both in vivo and vitro [81]. Similarly miR-125b-rich exosomes downregulate autophagy level through the p53/bnip3 signaling pathway to reduce death of cardiomyocytes [82]. Li et al. determined that miR-22 regulates cardiomyocyte autophagy and apoptosis by targeting p38a both in animal and cell experiments [83]. MiR-27a-5p also has been shown to relieve hypoxia-induced cardiomyocytes damage because of Atg7-mediated autophagy and apoptosis [84]. There is some new evidence indicated that stem cells and exosomes secreted by them have great potentials in regulating apoptosis of cardiomyocytes. Pan et al. claimed that exosomes derived by adipose-derived stem cells that modified by miR-146a could alleviate AMI-induced myocardial apoptosis by down-regulating early growth response factor 1 [85]. Another study showed that transplanted BM-MSCs paracrine VEGF that can regulate the expression of miR-23a, miR-92a and other miRNAs, and which has exerted anti-apoptotic effect on myocardial cells after MI [86]. It has been proved that BM-MSCs with a high expression of miR-133 are implanted into the infarction area of rats. It can promote the survival of BM-MSCs, also decrease the cardiomyocytes apoptosis rate and the infarction size [87]. In recent years, it is reported that there are many ncRNAs in exosome secreted by stem cells. Among several cardio-protective miRNAs of MSC exosomes. Luther et al. found that miR-21a-5p was the most abundant. MiR-21a-5pmediated cardio-protective effects is achieved by down-regulating PDCD4, FasL, PTEN and Peli1 and other pro-apoptotic gene [88]. Certainly, even at the highest content of miR-21a-5p, the role of other miRNAs in regulating myocardial cell apoptosis cannot be ignored. In the future, more unknown miRNAs in exosomes and their miRNA regulation 
networks should be further explored, even including circRNA and lncRNA.

In recent years, it has been shown that LncRNAs plays significant roles in regulating ischemia and hypoxia-induced cardiomyocyte death, lncRNA ANRIL has been indicated to protect cardiomyocytes from hypoxia and ischemia-induced loss through multiple signaling pathways. Shu et al. found that lncRNA ANRIL protected H9C2 cells from hypoxiainduced injury via miR-7-5p/SIRT1 axis [89], and Shi et al. demonstrated that LncRNA ANRIL regulated cardiomyocyte apoptosis through the IL33/ST2 pathway [90]. According to reports, camk2d-related transcript 1 (C2dat1) is a lncRNA associated with various ischemic diseases [91]. Huan et al. discovered that C2dat1 may negatively regulate miR-22, upregulated the expression of VEGF and enhanced the activation of PI3K/AKT/mTOR and JAK/STAT3 pathways to jointly protect cardiomyocytes [92]. LncRNA 2810403D21Rik/Mirf acts as a competitive endogenous RNA of miR-26a. Inhibiting lncRNA 2810403D21Rik/Mirf expression can promote upregulation of miR-26a and autophagy to reduce heart damage [93]. A cell experiments demonstrated that IncRNA TUG1-miR-124-Hic-5 mediated survival of H9C2 cells [94]. However, in view of Wu et al, overexpression of TUG1 aggravated hypoxia-induced cell injury by modulating the miR-145-5pBinp3 axis and activating the Wnt/catenin signaling pathway in H9C2 cells [95]. Two different results indicated that TUG1 may be a potential target for the treatment of AMI, but the specific mechanisms deserved further studied. In AMI rats, H19 can be used as an endogenous sponge to competitively bind to miR-22-3p and up-regulate the expression of KDM3A, thereby protecting myocardium from AMI-induced damage [96]. Du et al. revealed that silencing the expression of GAS5 can reduce hypoxia-induced apoptosis of $\mathrm{H} 9 \mathrm{C} 2$ cells, and protective mechanism may be that lncRNA GAS5 acted as miR-142-5p molecular sponge to inhibited the further expression of lncRNA GAS5 [97]. LncRNA MEG3 has also

\begin{tabular}{|c|c|c|c|c|}
\hline NcRNA & $\begin{array}{l}\text { Up/down } \\
\text { regulate }\end{array}$ & $\begin{array}{l}\text { Targets and/or signal } \\
\text { pathway }\end{array}$ & Function & Reference \\
\hline miR-363 & $\downarrow$ & Notch1 & $\begin{array}{l}\text { protect cardiomyocytes } \\
\text { hypoxia-induced apoptosis }\end{array}$ & [70] \\
\hline miR-155 & $\downarrow$ & QKI & $\begin{array}{l}\text { cut down the rate of cardiomyocytes } \\
\text { apoptosis in mice with MI }\end{array}$ & [71] \\
\hline miR-182-5p & $\uparrow$ & AKT/GSK-3 pathway & $\begin{array}{l}\text { show the anti-apoptotic effect in cell } \\
\text { experiments }\end{array}$ & [72] \\
\hline miR-30 & $\downarrow$ & CSE, H2S & $\begin{array}{l}\text { protected cardiomyocytes from } \\
\text { hypoxic damage }\end{array}$ & [73] \\
\hline $\operatorname{miR}-210$ & $\downarrow$ & CXCR4, mTOR, Smad & $\begin{array}{l}\text { mitigate hypoxia-induced } \mathrm{H} 9 \mathrm{C} 2 \text { cell } \\
\text { damage }\end{array}$ & [74] \\
\hline miR-21 & $\uparrow$ & $\begin{array}{l}\text { PTEN/AKT/FOXO3a } \\
\text { signal pathway }\end{array}$ & $\begin{array}{l}\text { inhibit TNF-a-induced cardiomyocyte } \\
\text { apoptosis in neonatal rats }\end{array}$ & [76] \\
\hline miR-145 & $\uparrow$ & AKT3/mTOR pathway & $\begin{array}{l}\text { inhibit myocardial infarction-induced } \\
\text { apoptosis both in vivo and vitro }\end{array}$ & [81] \\
\hline $\operatorname{miR}-125 b$ & $\uparrow$ & p53/bnip3 pathway & reduce death of cardiomyocytes & [82] \\
\hline miR-22 & $\uparrow$ & $\mathrm{p} 38 \mathrm{a}$ & $\begin{array}{l}\text { promote autophagy and inhibit } \\
\text { apoptosis }\end{array}$ & [83] \\
\hline miR-27a-5p & $\uparrow$ & Atg7 & $\begin{array}{l}\text { relieve hypoxia-induced } \\
\text { cardiomyocytes damage }\end{array}$ & [84] \\
\hline miR-146a & $\uparrow$ & $\begin{array}{l}\text { early growth response } \\
\text { factor } 1\end{array}$ & $\begin{array}{l}\text { alleviate AMI-induced myocardial } \\
\text { apoptosis }\end{array}$ & [85] \\
\hline miR-133 & $\uparrow$ & & $\begin{array}{l}\text { decrease the cardiomyocytes apoptosis } \\
\text { rate and the infarction size }\end{array}$ & [87] \\
\hline lnc ANRIL & $\uparrow$ & $\begin{array}{l}\text { miR-7-5p/SIRT1 signal } \\
\text { pathway }\end{array}$ & $\begin{array}{l}\text { protected } \mathrm{H} 9 \mathrm{C} 2 \text { cells from hypoxia- } \\
\text { induced injury }\end{array}$ & [89] \\
\hline
\end{tabular}

been found to increase FoxO1 activity under hypoxic conditions and promote cardiomyocyte apoptosis [98]. It is reported that suppressing the expression of lncRNA XIST can inhibit myocardial cell apoptosis in AMI rats by down-regulating miR-449 and up-regulating miR-130a-3p levels $[99,100]$. Both in cell and animal experiments, LncRNA MALAT1 was verified to play an important role in myocardial ischemia through various signaling pathways, including inhibiting the ERK/MAPK pathway, regulating Sirt 1 mediated by miRNA-217 and downstream PI3K/AKT as well as Notch signaling pathway $[101,102]$. HOX antisense intergenic RNA (HOTAIR), a $2.2 \mathrm{~kb}$ lncRNA, was originally described as a modulator of HOX gene expression. A recent study observed that adenoviral vector-driven HOTAIR overexpression significantly inhibited hypoxia-induced cardiomyocyte apoptosis partially based on the negative regulation of miR-1, while the adenovirus short hairpin HOTAIR knockout showed the opposite result [103]. Subsequently Zhang et al. discovered that HOTAIR also could be a sponge of miR-519d-3p in animal models. HOTAIR together with miR-519d-3p can alleviate myocardial infarction by inhibiting cardiomyocyte apoptosis and necrosis [104]. In oxygen-glucose deprivation (OGD) induced cardiomyocyte injury experiments, silencing circ_0010729 expression can activate mTOR and MEK/ERK pathways by up-regulating miR-145-5p, thereby protects cardiomyocytes from OGD-induced damage [105]. Antisense to the cerebellar degeneration related protein transcript, Cdrlas, also known as circular RNA sponge for miR-7, ciRS-7, recently and study showed that Cdrlas and miR-7a increased in a time-dependent manner within $24 \mathrm{~h}$ after MI or $12 \mathrm{~h}$ after hypoxia treatment, which suggested that Cdrlas and miR-7a may play important roles in MI-induced cardiomyocyte apoptosis. The anti-apoptotic mechanism may be that Cdrlas by inhibiting the function of miR-7a, upregulates the expression of target genes PARP and SP1, aggravates hypoxia-induced myocardial cell apoptosis and promotes myocardial infarction in mice [106] (Table 3). 


\begin{tabular}{|c|c|c|c|c|}
\hline lnc C2dat1 & $\uparrow$ & $\begin{array}{l}\mathrm{miR}-22, \\
\text { PI3K/AKT/mTOR, } \\
\text { JAK/STAT3 pathways }\end{array}$ & protect cardiomyocyte & [92] \\
\hline $\begin{array}{l}\text { lnc } \\
\text { 2810403D2 } \\
\text { 1Rik/Mirf } \\
\end{array}$ & $\downarrow$ & miR-26a & $\begin{array}{l}\text { promote autophagy to reduce heart } \\
\text { damage }\end{array}$ & [93] \\
\hline lnc TUG1 & $\uparrow$ & miR-124, Hic-5 & alleviate hypoxia injury & [94] \\
\hline lnc TUG1 & $\uparrow$ & $\begin{array}{l}\text { miR-145-5p-Binp3, } \\
\text { Wnt/catenin signaling } \\
\text { pathway }\end{array}$ & aggravate hypoxia-induced cell injury & [95] \\
\hline lnc H19 & $\uparrow$ & miR-22-3p, KDM3A & $\begin{array}{l}\text { protect myocardium from AMI- } \\
\text { induced damage }\end{array}$ & [96] \\
\hline lnc GAS5 & $\downarrow$ & miR-142-5p & $\begin{array}{l}\text { reduce hypoxia-induced apoptosis of } \\
\text { H9C } 2 \text { cells }\end{array}$ & [97] \\
\hline lnc MEG3 & $\uparrow$ & FoxO1 & promote cardiomyocyte apoptosis & [98] \\
\hline $\operatorname{lnc}$ XIST & $\downarrow$ & miR-449, miR-130a-3p & inhibit myocardial cell apoptosis & [99] [100] \\
\hline $\begin{array}{l}\text { lnc } \\
\text { MALAT1 }\end{array}$ & $\downarrow$ & $\begin{array}{l}\text { miRNA-217, } \\
\text { PI3K/AKT pathway }\end{array}$ & $\begin{array}{l}\text { aggravate hypoxia-induced } \\
\text { cardiomyocyte injury }\end{array}$ & [102] \\
\hline $\begin{array}{l}\operatorname{lnc} \\
\text { HOTAIR }\end{array}$ & $\uparrow$ & miR-1, miR-519d-3p & $\begin{array}{l}\text { inhibit cardiomyocyte apoptosis and } \\
\text { necrosis }\end{array}$ & [104] [103] \\
\hline $\begin{array}{l}\text { circ_001072 } \\
9\end{array}$ & $\downarrow$ & $\begin{array}{l}\text { miR-145-5p, mTOR and } \\
\text { MEK/ERK pathways }\end{array}$ & $\begin{array}{l}\text { protect cardiomyocytes from OGD- } \\
\text { induced damage }\end{array}$ & [105] \\
\hline lnc Cdrlas & $\uparrow \uparrow$ & miR-7a, PARP and SP1 & $\begin{array}{l}\text { aggravate hypoxia-induced myocardial } \\
\text { cell apoptosis and promotes } \\
\text { myocardial infarction in mice }\end{array}$ & {$[106]$} \\
\hline
\end{tabular}

Abbreviations: miR microRNA, Inc long non-coding RNA, circ circular RNA, OGD oxygen-glucose deprivation, AMI acute myocardial infarction

\section{Table 3 NcRNAs in inhibition of cardiomyocyte apoptosis}

\section{NCRNAs in angiogenesis in MI region}

Angiogenesis is an important part of cardiac repair after MI. It generates new blood vessels to restore blood flow and remove necrotic cell debris, promote tissue perfusion recovery, and transport nutrients and cytokines, which are of benefit to myocardial tissue repair after MI. It is reported that the degree of angiogenesis is related to myocardial remodeling following MI, and has an important effect on the prognosis of patients [107]. VEGF is one of major signaling molecule for angiogenesis. In recent years, ncRNAs have been found to promote or hinder angiogenesis after MI by regulating VEGF expression levels and multiplying downstream signaling pathways [108]. it is reported that miR-135a-3p hindered tissue repair angiogenesis by targeting the VEGF-HIP1-p38K signaling axis [109]. MiRNA-210 has been reported to have similar angiogenic effects [110]. miR-210 is a key regulator of angiogenesis and endothelial cell survival under hypoxia [91], However there is still some disputes about its specific regulatory molecular mechanism. Fan et al. claimed that miR-210 induced angiogenesis by up-regulating hepatocyte growth factor (HGF) expression rather than act in the VEGF target gene. HGF is similar to VEGF and is an important stimulator of angiogenesis [91]. Na et al. proposed that miR-210-efna3 dependent mechanism involved in process of angiogenesis. They found that miR-210 was highly enriched in MSC-extracellular vesicle (EVs), which could reduce the expression of Efna3 in human umbilical vein endothelial cells, then promote angiogenesis and improve infarcted heart function, conversely the angiogenesis effect of miR-210 silenced MSC-EVs disappeared [111]. These studies indicate that miRNAs can regulate vascular activity after MI through different regulatory factors and signaling pathways.
Notch homologue 1, which was predicted as one of the primary targets of miR-34a, is a regulator of vascular smooth muscle cell (VSMC) function and arterial reconstruction. miR-34a inhibited VSMC and neointimal proliferation by regulating the expression level of Notch gene [112]. Zhang et al. reported that miR-24 prevented endothelial nitric oxide synthase expression and vascular endothelial cell proliferation by regulating Sp1 [113, while the down-regulation of miR-218 could inhibit phthalic acid related transcription factor to stimulate angiogenesis and improve cardiac function in MI rats [114]. Ma et al. found that injection of MSC-derived exosomes rich in miR-132 into ischemic myocardium of rats significantly enhanced the formation of neovascularization around the infarct. The molecular mechanism is that miR-132 directly inhibits RASA1 and Spred1 to enhance the Ras-MAPK signaling pathway [115]. According to the analysis of miR-spectrum and bioinformatic, miR-495 was thought to have anti-angiogenesis potential. LIANG et al. discovered that inhibition of miR-495 could promote the differentiation of human induced pluripotent stem cell (hIPSC) into endothelial cells, enhance therapeutic angiogenesis of hIPSC around the infarct edge [116]. MiR223-3p has been identified as the core miRNA of ischemia- cerebral microvascular endothelial cells (CMEC) angiogenesis, which can inhibit the migration and proliferation of ischemia-CMEC angiogenesis by regulating the Rps6kb1/HIF-1 $\alpha$ signaling pathway, thereby weakening the ability of angiogenesis [117]. Recently, in pre-clinical animal models of MI, it was found that EVs equipped with miR-21 effectively introduced miR-21 into cardiomyocytes and endothelial cells, then activated PTEN/Akt signaling pathway, stimulated endothelial cells to express VEGF and promoted angiogenesis [118]. The above studies indicated another potential role of miR-21 in regulating angiogenesis in addition to regulating myocardial fibrosis. Similar to miR-21, miR-27b also has a 
protective effect on the angiogenesis and infarcted heart function [119]. Recently, as $\mathrm{Su}$ et al. reported that leucine-rich alpha-2-glycoprotein-1 (LRG1) is negative regulated by miR-494, further found that overexpression of miR-494 may inhibited LRG1 and inactivated the Wnt signaling, thus accelerating the proliferation and migration of vascular endothelial cells after MI [120]. In recent years, although many miRNAs have been found to play roles in the mediation of vascular activity after MI, however, most of these studies are superficial and isolated, and the miRNA with good effects and it's deeper mechanisms still need to be further explored and discovered.

Even though some studies have shown that some lncRNA and circRNA are relevant to the regulation of the behavior of vascular endothelial cells and VSMC in a large number of tumors and cerebrovascular disease models [121], however there are a few studies which revealed the specific regulation of the angiogenesis of lncRNA and circRNA after MI in recent years. Garikipati et al. pointed out the view that a high level of circFndc $3 b$ in the ischemic myocardium can inhibit angiogenesis, the main mechanism was that circFndc $3 b$ enhanced the expression and signal transduction of VEGF-A [122]. CircNfix has been found that not only adjusts the potential of cardiac muscle cell proliferation, but also can plays an important role of angiogenesis regulation via circNfix/miR-214/Gsk3 $\beta$ pathway after MI [31]. Although there are few studies on role of lncRNA and circRNA in angiogenesis after MI, their ability to modulate the angiogenic activity of tumor cells suggests that they may also have a certain therapeutic potential in modulating the vascular activity following MI, which needs to be actively explored by more scientists (Table 4).

\begin{tabular}{|l|l|l|l|l|}
\hline NcRNA & $\begin{array}{l}\text { Up/down } \\
\text { regulate }\end{array}$ & $\begin{array}{l}\text { Targets and/or } \\
\text { signal pathway }\end{array}$ & Function & Reference \\
\hline $\begin{array}{l}\text { miR-135a- } \\
3 p\end{array}$ & $\uparrow$ & $\begin{array}{l}\text { VEGF-HIP1-p38K } \\
\text { signal pathway }\end{array}$ & hinder tissue repair angiogenesis & {$[109]$} \\
\hline miR-210 & $\uparrow$ & HGF & induce angiogenesis & {$[91]$} \\
\hline miR-210 & $\uparrow$ & efna3 & $\begin{array}{l}\text { promote angiogenesis and improve infarcted } \\
\text { heart function }\end{array}$ & {$[111]$} \\
\hline miR-34a & $\uparrow$ & Notch 1 & inhibit neointimal proliferation & {$[112]$} \\
\hline miR-218 & $\downarrow$ & $\begin{array}{l}\text { phthalic acid related } \\
\text { transcription factor }\end{array}$ & $\begin{array}{l}\text { stimulate angiogenesis and improve cardiac } \\
\text { function in MI }\end{array}$ & {$[114]$} \\
\hline miR-24 & $\uparrow$ & $\begin{array}{l}\text { Sp1, eNOs } \\
\text { prevent vascular endothelial cell } \\
\text { proliferation }\end{array}$ & {$[113]$} \\
\hline miR-132 & $\uparrow$ & $\begin{array}{l}\text { RASA1, Spred1, } \\
\text { Ras-MAPK signal } \\
\text { pathway }\end{array}$ & $\begin{array}{l}\text { enhance the formation of neovascularization } \\
\text { around the infarct }\end{array}$ & {$[115]$} \\
\hline miR-495 & $\downarrow$ & $\begin{array}{l}\text { promote the differentiation of hIPSC into } \\
\text { endothelial cells }\end{array}$ & {$[116]$} \\
\hline miR-223-3p & $\uparrow$ & $\begin{array}{l}\text { Rps6kb1/HIF-1 } \alpha \\
\text { signaling pathway }\end{array}$ & $\begin{array}{l}\text { inhibit the migration and proliferation of } \\
\text { ischemia-CMEC angiogenesis }\end{array}$ & {$[117]$} \\
\hline miR-21 & $\uparrow$ & PTEN/Akt pathway & promote angiogenesis & accelerate the proliferation and migration of \\
vascular endothelial cells after MI & {$[120]$} \\
\hline miR-494 & $\uparrow$ & LRG1, Wnt & inhibit angiogenesis & promote angiogenesis \\
\hline circ Fndc3b & $\uparrow$ & VEGF-A & {$[122]$} \\
\hline circ Nfix & $\uparrow$ & signal pathway & [31] \\
\hline
\end{tabular}

Abbreviations: miR microRNA, Inc long non-coding RNA, circ circular RNA, MI myocardial infarction, hIPSC human induced pluripotent stem cell, CMEC cerebral microvascular endothelial cell

\section{Table 4 NcRNAs in angiogenesis in MI region}

\section{Conclusion}

In summary, ncRNAs, such as miRNA, lncRNA and circRNA can individually or synergistically regulate the repair process after MI, which involved in the process of cardiomyocyte apoptosis, myocardial regeneration, fibroblast activation and angiogenesis following MI. MI is a complex process with multiple stages and successive activation of various cytokines and mechanisms. ncRNAs have multiple targets and can form circRNA/ lncRNA-miRNA-mRNA regulatory network, which all suggest that ncRNAs are potential therapeutic targets for repair of MI and is worthy of further in-depth study.

Competing interest: None declared.

Funding: This research was funded by NFSC (81860783)

\section{References}

1. Reddy, K., Khaliq, A. \& Henning, R. J. Recent advances in the diagnosis and treatment of acute myocardial infarction. World journal of cardiology 7, 243-276,

2. Kikuchi, K. \& Poss, K. D. Cardiac regenerative capacity and mechanisms. Annu Rev Cell Dev Biol 28, 719-741, doi:10.1146/annurev-cellbio-101011-155739 (2012).

3. Prabhu, S. D. \& Frangogiannis, N. G. The Biological Basis for Cardiac Repair After Myocardial Infarction: From Inflammation to Fibrosis. Circulation research 119, 91-112, doi:10.1161/CIRCRESAHA.116.303577 (2016).

4. Gnecchi, M., Pisano, F. \& Bariani, R. microRNA and Cardiac Regeneration. Adv Exp Med Biol 887, 119-141, doi:10.1007/978-3-319-22380-3_7 (2015).

5. Munarin, F., Kant, R. J., Rupert, C. E., Khoo, A. \& Coulombe, 
K. L. K. Engineered human myocardium with local release of angiogenic proteins improves vascularization and cardiac function in injured rat hearts. Biomaterials 251, 15, doi:10.1016/j.biomaterials.2020.120033 (2020).

6. Barile, L. et al. Extracellular vesicles from human cardiac progenitor cells inhibit cardiomyocyte apoptosis and improve cardiac function after myocardial infarction. Cardiovasc Res 103, 530-541, doi:10.1093/cvr/cvu167 (2014).

7. Huang, S. \& Frangogiannis, N. G. Anti-inflammatory therapies in myocardial infarction: failures, hopes and challenges. Br J Pharmacol 175, 1377-1400, doi:10.1111/bph.14155 (2018).

8. McLaughlin, S. et al. Injectable human recombinant collagen matrices limit adverse remodeling and improve cardiac function after myocardial infarction. Nature communications 10, 48664866, doi:10.1038/s41467-019-12748-8 (2019).

9. Chiarella-Redfern, H. H., Rayner, K. J. \& Suuronen, E. J. Spatiotemporal expression patterns of microRNAs in remodelling and repair of the infarcted heart. Histol Histopathol 30, 141-149, doi:10.14670/HH-30.141 (2015).

10. Esteller, M. Non-coding RNAs in human disease. Nat Rev Genet 12, 861-874, doi:10.1038/nrg3074 (2011).

11. Fasanaro, P., D'Alessandra, Y., Magenta, A., Pompilio, G. \& Capogrossi, M. C. microRNAs: Promising Biomarkers and Therapeutic Targets of Acute Myocardial Ischemia. Curr Vasc Pharmacol 13, 305-315, doi:10.2174/15701611113119990011 (2015).

12. An, Y., Furber, K. L. \& Ji, S. Pseudogenes regulate parental gene expression via ceRNA network. J Cell Mol Med 21, 185-192, doi:10.1111/jcmm.12952 (2017).

13. Pandey, R. \& Ahmed, R. P. MicroRNAs Inducing Proliferation of Quiescent Adult Cardiomyocytes. Cardiovasc Regen Med 2, doi:10.14800/crm.519 (2015).

14. Zhang, Y. et al. Cardiac Repair With a Novel Population of Mesenchymal Stem Cells Resident in the Human Heart. Stem Cells 33, 3100-3113, doi:10.1002/stem.2101 (2015).

15. Cho, G. S., Fernandez, L. \& Kwon, C. Regenerative medicine for the heart: perspectives on stem-cell therapy. Antioxid Redox Signal 21, 2018-2031, doi:10.1089/ars.2014.6063 (2014).

16. Wen, Z. et al. Local activation of cardiac stem cells for postmyocardial infarction cardiac repair. Journal of Cellular \& Molecular Medicine 16, 2549-2563 (2012).

17. Liu, Q. et al. Identification of apoptosis-related microRNAs and their target genes in myocardial infarction post-transplantation with skeletal myoblasts. J Transl Med 13, 270, doi:10.1186/s12967-015-0603-0 (2015).

18. Lam, N. T. \& Sadek, H. A. Neonatal Heart Regeneration: Comprehensive Literature Review. Circulation 138, 412-423, doi:10.1161/circulationaha.118.033648 (2018).

19. Yang, Y. et al. MicroRNA-34a Plays a Key Role in Cardiac Repair and Regeneration Following Myocardial Infarction. Circ Res 117, 450-459, doi:10.1161/CIRCRESAHA.117.305962 (2015).

20. Shi, B., Deng, W., Long, X., Zhao, R. \& Cao, S. miR-21 increases c-kit + cardiac stem cell proliferation in vitro through PTEN/PI3K/Akt signaling. Peerj 5, e2859 (2017).

21. Huang, W. et al. Loss of microRNA-128 promotes cardiomyocyte proliferation and heart regeneration. Nature Communications 9, doi:10.1038/s41467-018-03019-z (2018).

22. Pandey, R. et al. MicroRNA-1825 induces proliferation of adult cardiomyocytes and promotes cardiac regeneration post ischemic injury. Am J Transl Res 9, 3120-3137 (2017).

23. Wang, L. L. et al. Local and sustained miRNA delivery from an injectable hydrogel promotes cardiomyocyte proliferation and functional regeneration after ischemic injury. Nat Biomed Eng
1, 983-992, doi:10.1038/s41551-017-0157-y (2017).

24. Pierluigi et al. Single-Dose Intracardiac Injection of ProRegenerative MicroRNAs Improves Cardiac Function After Myocardial Infarction. Circulation Research (2017).

25. Wang, J. et al. A long noncoding RNA NR_045363 controls cardiomyocyte proliferation and cardiac repair. Journal of Molecular and Cellular Cardiology 127, 105-114, doi:10.1016/j.yjmcc.2018.12.005 (2019).

26. Chen, Y. et al. Long Non-coding RNA ECRAR Triggers Postnatal Myocardial Regeneration by Activating ERK1/2 Signaling. Mol Ther 27, 29-45, doi:10.1016/j.ymthe.2018.10.021 (2019).

27. Cai, B. Z. et al. Targeting LncDACH1 promotes cardiac repair and regeneration after myocardium infarction. Cell Death and Differentiation, doi:10.1038/s41418-020-0492-5.

28. Teng, Y. et al. LncRNA RMRP accelerates hypoxia-induced injury by targeting miR-214-5p in $\mathrm{H} 9 \mathrm{c} 2$ cells. Journal of Pharmacological Sciences 142, 69-78, doi:10.1016/j.jphs.2019.07.014 (2020).

29. Chen, G. J. et al. Loss of long non-coding RNA CRRL promotes cardiomyocyte regeneration and improves cardiac repair by functioning as a competing endogenous RNA. Journal of Molecular and Cellular Cardiology 122, 152-164, doi:10.1016/j.yjmcc.2018.08.013 (2018).

30. Ponnusamy, M. et al. Long Noncoding RNA CPR (Cardiomyocyte Proliferation Regulator) Regulates Cardiomyocyte Proliferation and Cardiac Repair. Circulation 139, 2668-2684, doi:10.1161/circulationaha.118.035832 (2019).

31. Huang, S. L. et al. Loss of Super-Enhancer-Regulated circRNA Nfix Induces Cardiac Regeneration After Myocardial Infarction in Adult Mice. Circulation 139, 2857-2876, doi:10.1161/circulationaha.118.038361 (2019).

32. Parizadeh, S. M. et al. Stem cell therapy: A novel approach for myocardial infarction. Journal of Cellular Physiology 234, 16904-16912, doi:10.1002/jcp.28381 (2019).

33. Goradel, N. H. et al. Stem Cell Therapy: A New Therapeutic Option for Cardiovascular Diseases. J Cell Biochem 119, 95104, doi:10.1002/jcb.26169 (2018).

34. Müller, P., Lemcke, H. \& David, R. Stem Cell Therapy in Heart Diseases - Cell Types, Mechanisms and Improvement Strategies. Cell Physiol Biochem 48, 2607-2655, doi:10.1159/000492704 (2018).

35. Yang, W. G., Zheng, H., Dan, J. G., Wang, C. X. \& Xue, S. Mesenchymal stem cells were affected by up-regulation of miRNA-21 in vitro. International Journal of Clinical and Experimental Pathology 11, 27-37 (2018).

36. Chen, J. et al. mir-17-92 cluster is required for and sufficient to induce cardiomyocyte proliferation in postnatal and adult hearts. Circ Res 112, 1557-1566, doi:10.1161/CIRCRESAHA.112.300658 (2013).

37. Huang, F. et al. Overexpression of MicroRNA-1 Improves the Efficacy of Mesenchymal Stem Cell Transplantation after Myocardial Infarction. Cardiology 125, 18-30, doi:10.1159/000347081 (2013).

38. Ding, L. et al. Role of microRNA-1 and microRNA-133 in myocardial differentiation of mouse embryonic stem cells. Chinese Heart Journal (2015).

39. Chen, Y. Q. et al. MicroRNA-133 overexpression promotes the therapeutic efficacy of mesenchymal stem cells on acute myocardial infarction. Stem Cell Research \& Therapy 8, doi:10.1186/s13287-017-0722-z (2017).

40. Dakhlallah, D. et al. MicroRNA-133a Engineered Mesenchymal Stem Cells Augment Cardiac Function and Cell Survival in the Infarct Heart. Journal of Cardiovascular Pharmacology 65, 241- 
251, doi:10.1097/fjc.0000000000000183 (2015).

41. Mao, J., Lv, Z. \& Zhuang, Y. MicroRNA-23a is involved in tumor necrosis factor-alpha induced apoptosis in mesenchymal stem cells and myocardial infarction. Exp Mol Pathol 97, 23-30, doi:10.1016/j.yexmp.2013.11.005 (2014).

42. Garikipati, V. N. et al. Negative Regulation of miR-375 by Interleukin-10 Enhances Bone Marrow-Derived Progenitor Cell-Mediated Myocardial Repair and Function After Myocardial Infarction. Stem Cells 33, 3519-3529, doi:10.1002/stem.2121 (2015).

43. Singla, D. K. Stem cells and exosomes in cardiac repair. Current Opinion in Pharmacology 27 (2016).

44. Moghaddam, A. S. et al. Cardioprotective microRNAs: Lessons from stem cell-derived exosomal microRNAs to treat cardiovascular disease. Atherosclerosis 285, 1-9, doi:10.1016/j.atherosclerosis.2019.03.016 (2019).

45. Rog-Zielinska, E. A., Norris, R. A., Kohl, P. \& Markwald, R. The Living Scar--Cardiac Fibroblasts and the Injured Heart. Trends Mol Med 22, 99-114, doi:10.1016/j.molmed.2015.12.006 (2016).

46. Van, d. B., Susanne W. M. et al. Myocardial remodeling after infarction: the role of myofibroblasts. Nature Reviews Cardiology 7, 30-37 (2009).

47. Chen, H. U., Zhang, Y. \& Cardiology, D. O. Research progress of non-coding RNA effects in myocardial fibrosis. Chinese Journal of Cardiovascular Rehabilitation Medicine (2017).

48. Peng, Y., Chao, F. F., Cai, Y. P., Teng, W. \& Qiu, C. G. MiR-126 inhibits the proliferation of myocardial fibroblasts by regulating EGFL7-mediated EGFR signal pathway. International Journal of Clinical and Experimental Medicine 10, 6158-6166 (2017).

49. Tao, H., Chen, Z. W., Yang, J. J. \& Shi, K. H. MicroRNA-29a suppresses cardiac fibroblasts proliferation via targeting VEGFA/MAPK signal pathway. International Journal of Biological Macromolecules 88, 414-423, doi:10.1016/j.ijbiomac.2016.04.010 (2016).

50. Zhao, T. et al. Platelet-derived growth factor-D promotes fibrogenesis of cardiac fibroblasts. American journal of physiology. Heart and circulatory physiology 304, H1719H1726, doi:10.1152/ajpheart.00130.2013 (2013).

51. Wang, L. et al. MicroRNA-9 regulates cardiac fibrosis by targeting PDGFR-beta in rats. Journal of Physiology and Biochemistry 72, 213-223, doi:10.1007/s13105-016-0471-y (2016).

52. Dong, H. et al. MicroRNA-214 exerts a Cardio-protective effect by inhibition of fibrosis. Anat Rec (Hoboken) 299, 1348-1357, doi:10.1002/ar.23396 (2016).

53. Xin, Z. MicroRNA-101a inhibits cardiac fibrosis induced by hypoxia via targeting TGF $\beta$ RI on cardiac fibroblasts. Cellular physiology and biochemistry: international journal of experimental cellular physiology, biochemistry, and pharmacology 1 (2015).

54. Xiao, L. et al. Effects of miR-29a and miR-101a Expression on Myocardial Interstitial Collagen Generation After Aerobic Exercise in Myocardial-infarcted Rats. Archives of Medical Research 48, 27-34, doi:10.1016/j.arcmed.2017.01.006 (2017).

55. Bradham, D. M., Igarashi, A., Potter, R. L. \& Grotendorst, G. R. Connective tissue growth factor: a cysteine-rich mitogen secreted by human vascular endothelial cells is related to the $\mathrm{SRC}$-induced immediate early gene product CEF-10. J Cell Biol 114, 1285-1294, doi:10.1083/jcb.114.6.1285 (1991).

56. Chen, L. W. et al. miR-30a attenuates cardiac fibrosis in rats with myocardial infarction by inhibiting CTGF. Experimental and Therapeutic Medicine 15, 4318-4324, doi:10.3892/etm.2018.5952 (2018).
57. He, Q., Wang, F. F., Honda, T., Li, J. \& Redington, A. N. Loss of Mir-144 Signaling Interrupts Extracellular Matrix Remodeling After Myocardial Infarction Leading to Worsened Cardiac Function. Circulation 136 (2017).

58. Valkov, N. et al. MicroRNA-1-Mediated Inhibition of Cardiac Fibroblast Proliferation Through Targeting Cyclin D2 and CDK6. Frontiers in Cardiovascular Medicine 6, doi:10.3389/fcvm.2019.00065 (2019).

59. Du, W. J. et al. MicroRNA-328, a Potential Anti-Fibrotic Target in Cardiac Interstitial Fibrosis. Cellular Physiology and Biochemistry 39, 827-836, doi:10.1159/000447793 (2016).

60. Li, R. et al. Sp1 Mediates a Therapeutic Role of MiR-7a/b in Angiotensin II-Induced Cardiac Fibrosis via Mechanism Involving the TGF-beta and MAPKs Pathways in Cardiac Fibroblasts. PLoS One 10, e0125513, doi:10.1371/journal.pone.0125513 (2015).

61. Liang, H. et al. A novel reciprocal loop between microRNA-21 and TGF $\beta$ RIII is involved in cardiac fibrosis. Int J Biochem Cell Biol 44, 2152-2160 (2012).

62. Chen, C. H., Hsu, S. Y., Chiu, C. C. \& Leu, S. MicroRNA-21 Mediates the Protective Effect of Cardiomyocyte-Derived Conditioned Medium on Ameliorating Myocardial Infarction in Rats. Cells 8, doi:10.3390/cells8080935 (2019).

63. Sun, L. Y. et al. Circ_LAS1L regulates cardiac fibroblast activation, growth, and migration through miR-125b/SFRP5 pathway. Cell Biochemistry and Function 38, 443-450, doi:10.1002/cbf.3486 (2020).

64. Qu, X. F. et al. MIAT Is a Pro-fibrotic Long Non-coding RNA Governing Cardiac Fibrosis in Post-infarct Myocardium. Scientific Reports 7, doi:10.1038/srep42657 (2017).

65. Sun, F. et al. LncRNA PCFL promotes cardiac fibrosis via miR378/GRB2 pathway following myocardial infarction. Journal of Molecular and Cellular Cardiology 133, 188-198, doi:10.1016/j.yjmcc.2019.06.011 (2019).

66. Zhang, J. C. et al. Effect of lncRNA GAS5 on rats with acute myocardial infarction through regulating miR-21. European Review for Medical and Pharmacological Sciences 23, 85738579, doi:10.26355/eurrev_201910_19173 (2019).

67. Choong, O. K. et al. Hypoxia-induced H19/YB-1 cascade modulates cardiac remodeling after infarction. Theranostics 9, 6550-6567, doi:10.7150/thno.35218 (2019).

68. Huang, Z. W., Tian, L. H., Yang, B. \& Guo, R. M. Long Noncoding RNA H19 Acts as a Competing Endogenous RNA to Mediate CTGF Expression by Sponging miR-455 in Cardiac Fibrosis. DNA and Cell Biology 36, 759-766, doi:10.1089/dna.2017.3799 (2017).

69. Takemura, G. \& Fujiwara, H. Role of apoptosis in remodeling after myocardial infarction. Pharmacol Ther 104, 1-16, doi:10.1016/j.pharmthera.2004.07.005 (2004).

70. Meng, X. X. et al. Inhibition of miR-363 protects cardiomyocytes against hypoxia-induced apoptosis through regulation of Notch signaling. Biomedicine \& Pharmacotherapy 90, 509-516, doi:10.1016/j.biopha.2017.03.080 (2017).

71. Guo, J., Liu, H.-B., Sun, C., Yan, X.-Q. \& Du, Z.-M. MicroRNA-155 Promotes Myocardial Infarction-Induced Apoptosis by Targeting RNA-Binding Protein QKI. Oxidative medicine and cellular longevity 2019, 1-14 (2019).

72. Yao, L., Zhou, Q. S., Wang, L. \& Hou, G. MicroRNA-182-5p protects H9c2 cardiomyocytes from hypoxia-induced apoptosis by down-regulation of PTEN. International Journal of Clinical and Experimental Pathology 10, 5220-5226 (2017).

73. Shen, Y. et al. miRNA-30 family inhibition protects against cardiac ischemic injury by regulating cystathionine- $\gamma$-lyase expression. Antioxid Redox Signal 22, 224-240, 
doi:10.1089/ars.2014.5909 (2015).

74. Feng, M. et al. MicroRNA-210 aggravates hypoxia-induced injury in cardiomyocyte H9c2 cells by targeting CXCR4. Biomedecine \& Pharmacotherapie 102, 981-987 (2018).

75. Ceviker, K., Bagci, O. \& Yazkan, R. Unknown Aspects of Wellknown Cardiovascular Diseases: Identification of Novel miRNA Genes. Journal of Clinical and Analytical Medicine 7, 575-580, doi:10.4328/jcam.3991 (2016).

76. Wang, Z. H. et al. miRNA-21 Expression in the Serum of Elderly Patients with Acute Myocardial Infarction. Medical Science Monitor 23, 5728-5734, doi:10.12659/msm.904933 (2017).

77. Liu, Y. et al. A feedback regulatory loop between HIF-1 $\alpha$ and miR-21 in response to hypoxia in cardiomyocytes. FEBS Letters: For the Rapid Publication of Short Reports in Biochemistry, Biophysics and Molecular Biology 588, 31373146 (2014).

78. Xue, X. et al. Delivery of MicroRNA-1 Inhibitor by Dendrimerbased Nanovector: an Early Targeting Therapy for Myocardial Infarction in Mice. Nanomedicine, S1549963417305828 (2017).

79. $\mathrm{Xu}, \mathrm{Y}$. et al. Combinatorial microRNAs suppress hypoxiainduced cardiomyocytes apoptosis. Cell Physiol Biochem 37, 921-932, doi:10.1159/000430219 (2015).

80. Wang, L. J., Wang, J. Q., Cretoiu, D., Li, G. P. \& Xiao, J. J. Exercise-mediated regulation of autophagy in the cardiovascular system. J. Sport Health Sci. 9, 203-210, doi:10.1016/j.jshs.2019.10.001 (2020).

81. Yan, L. Q. et al. miRNA-145 inhibits myocardial infarctioninduced apoptosis through autophagy via Akt3/mTOR signaling pathway in vitr and in vivo. International Journal of Molecular Medicine 42, 1537-1547, doi:10.3892/ijmm.2018.3748 (2018).

82. Xiao, C. et al. Transplanted Mesenchymal Stem Cells Reduce Autophagic Flux in Infarcted Hearts via the Exosomal Transfer of mir-125b. Circulation Research, CIRCRESAHA.118.312758- (2018).

83. $\mathrm{Li}, \mathrm{G}$. et al. miR-22 regulates starvation-induced autophagy and apoptosis in cardiomyocytes by targeting p38 $\alpha$. Biochemical \& Biophysical Research Communications, S0006291X16313432 (2016).

84. Zhang, J., Qiu, W., Ma, J., Wang, Y. \& Li, M. miR-27a-5p Attenuates Hypoxia-induced Rat Cardiomyocyte Injury by Inhibiting Atg7. International Journal of Molecular ences 20, 2418 (2019).

85. Pan, J., Alimujiang, M., Chen, Q., Shi, H. \& Luo, X. Exosomes derived from miR-146a-modified adipose-derived stem cells attenuate acute myocardial infarction-induced myocardial damage via downregulation of early growth response factor 1 . Journal of Cellular Biochemistry 120 (2019).

86. Song, Y. S. et al. Bone marrow mesenchymal stem cell-derived vascular endothelial growth factor attenuates cardiac apoptosis via regulation of cardiac miRNA-23a and miRNA-92a in a rat model of myocardial infarction. Plos One 12, e0179972 (2017).

87. Chen, Y. et al. MicroRNA-133 overexpression promotes the therapeutic efficacy of mesenchymal stem cells on acute myocardial infarction. Stem Cell Research \& Therapy 8, 268 (2017).

88. Luther, K. M. et al. Exosomal miR-21a-5p mediates cardioprotection by mesenchymal stem cells. Journal of Molecular and Cellular Cardiology 119, 125-137, doi:10.1016/j.yjmcc.2018.04.012 (2018).

89. Shu, L. et al. lncRNA ANRIL protects H9c2 cells against hypoxia-induced injury through targeting the miR-7-5p/SIRT1 axis. J Cell Physiol 235, 1175-1183, doi:10.1002/jcp.29031 (2020).
90. Yang, J., Huang, X., Hu, F., Fu, X. \& Chen, K. LncRNA ANRIL knockdown relieves myocardial cell apoptosis in acute myocardial infarction by regulating IL-33/ST2. Cell cycle (Georgetown, Tex.) 18, 1-11 (2019).

91. Fan, Z. G. et al. MicroRNA-210 promotes angiogenesis in acute myocardial infarction. Molecular Medicine Reports 17, 56585665, doi:10.3892/mmr.2018.8620 (2018).

92. Sun, H., Shi, K., Xie, D., Zhang, H. \& Yu, B. Long noncoding RNA C2dat1 protects $\mathrm{H} 9 \mathrm{c} 2$ cells against hypoxia injury by downregulating miR-22. J Cell Physiol 234, 20623-20633, doi:10.1002/jcp.28667 (2019).

93. Liang, H. H. et al. LncRNA 2810403D21Rik/Mirf promotes ischemic myocardial injury by regulating autophagy through targeting Mir26a. Autophagy 16, 1077-1091, doi:10.1080/15548627.2019.1659610 (2020).

94. Jiang, N. X., Xia, J. W., Jiang, B., Xu, Y. H. \& Li, Y. S. TUG1 alleviates hypoxia injury by targeting miR-124 in H9c2 cells. Biomedicine \& Pharmacotherapy 103, 1669-1677, doi:10.1016/j.biopha.2018.04.191 (2018).

95. Wu, Z. W., Zhao, S. J., Li, C. F. \& Liu, C. Q. LncRNA TUG1 serves an important role in hypoxia-induced myocardial cell injury by regulating the miR-145-5p-Binp3 axis. Molecular Medicine Reports 17, 2422-2430, doi:10.3892/mmr.2017.8116 (2018).

96. Zhang, B. F. et al. LncRNA H19 ameliorates myocardial infarction-induced myocardial injury and maladaptive cardiac remodelling by regulating KDM3A. Journal of Cellular and Molecular Medicine 24, 1099-1115, doi:10.1111/jcmm.14846 (2020).

97. Du, J., Yang, S. T., Liu, J., Zhang, K. X. \& Leng, J. Y. Silence of LncRNA GAS5 Protects Cardiomyocytes H9c2 against Hypoxic Injury via Sponging miR-142-5p. Molecules and Cells 42, $397-$ 405, doi:10.14348/molcells.2018.0180 (2019).

98. Zhao, L. Y., Li, X., Gao, L. \& Xu, Y. LncRNA MEG3 accelerates apoptosis of hypoxic myocardial cells via FoxO1 signaling pathway. European Review for Medical and Pharmacological Sciences 23, 334-340, doi:10.26355/eurrev_201908_18665 (2019).

99. Zhang, M. et al. Silence of lncRNA XIST represses myocardia cell apoptosis in rats with acute myocardial infarction through regulating miR-449. European Review for Medical and Pharmacological Sciences 23, 8566-8572, doi:10.26355/eurrev_201910_19172 (2019).

100. Zhou, T., Qin, G. W., Yang, L. H., Xiang, D. K. \& Li, S. N. LncRNA XIST regulates myocardial infarction by targeting miR-130a-3p. Journal of Cellular Physiology 234, 8659-8667, doi:10.1002/jcp.26327 (2019).

101. Fan, Y. Z., Huang, H., Wang, S., Tan, G. J. \& Zhang, Q. Z. Effect of lncRNA MALAT1 on rats with myocardial infarction through regulating ERK/MAPK signaling pathway. European Review for Medical and Pharmacological Sciences 23, 9041-9049, doi:10.26355/eurrev_201910_19306 (2019).

102. Yao, Y., Fan, X., Yu, B., Li, T. F. \& Zhang, Y. Knockdown of long noncoding RNA Malat1 aggravates hypoxia-induced cardiomyocyte injury by targeting miR-217. Advances in Clinical and Experimental Medicine 28, 719-728, doi:10.17219/acem/93878 (2019).

103. Gao, L. et al. Circulating Long Noncoding RNA HOTAIR is an Essential Mediator of Acute Myocardial Infarction. Cellular Physiology and Biochemistry 44, 1497-1508, doi:10.1159/000485588 (2017).

104. Zhang, D. Y. et al. IncRNA HOTAIR Protects Myocardial Infarction Rat by Sponging miR-519d-3p. Journal of Cardiovascular Translational Research 12, 171-183, 
doi:10.1007/s12265-018-9839-4 (2019).

105. Jin, Q. F. \& Chen, Y. Y. Silencing circular RNA circ_0010729 protects human cardiomyocytes from oxygen-glucose deprivation-induced injury by up-regulating microRNA-145-5p. Molecular and Cellular Biochemistry 462, 185-194, doi:10.1007/s11010-019-03621-9 (2019).

106. Geng, H. H. et al. The Circular RNA Cdrlas Promotes Myocardial Infarction by Mediating the Regulation of miR-7a on Its Target Genes Expression. Plos One 11, e0151753- (2016).

107. Badimon, L. \& Borrell, M. Microvasculature Recovery by Angiogenesis After Myocardial Infarction. Curr Pharm Des 24, 2967-2973, doi:10.2174/1381612824666180629162726 (2018).

108. Kir, D., Schnettler, E., Modi, S. \& Ramakrishnan, S. Regulation of angiogenesis by microRNAs in cardiovascular diseases. Angiogenesis 21, 699-710, doi:10.1007/s10456-018-9632-7 (2018).

109. Icli, B. et al. MicroRNA-135a-3p regulates angiogenesis and tissue repair by targeting p38 signaling in endothelial cells. Faseb Journal 33, 5599-5614, doi:10.1096/fj.201802063RR (2019).

110. Arif, M. et al. MicroRNA-210-mediated proliferation, survival, and angiogenesis promote cardiac repair post myocardial infarction in rodents. Journal of Molecular Medicine (2017).

111. Wang, N. et al. Mesenchymal stem cells-derived extracellular vesicles, via miR-210, improve infarcted cardiac function by promotion of angiogenesis. Biochim Biophys Acta Mol Basis Dis 1863, 2085-2092, doi:10.1016/j.bbadis.2017.02.023 (2017).

112. Chen, Q. et al. miRNA-34a reduces neointima formation through inhibiting smooth muscle cell proliferation and migration. J Mol Cell Cardiol 89, 75-86, doi:10.1016/j.yjmcc.2015.10.017 (2015).

113. Zhang, W. Y. et al. Roles of miRNA-24 in regulating endothelial nitric oxide synthase expression and vascular endothelial cell proliferation. Molecular and Cellular Biochemistry 405, 281289, doi:10.1007/s11010-015-2418-y (2015).
114. Qian, L. F. et al. Downregulation of microRNA-218 is cardioprotective against cardiac fibrosis and cardiac function impairment in myocardial infarction by binding to MITF. AgingUs 11, 5368-5388, doi:10.18632/aging.102112 (2019).

115. Ma, T. et al. MicroRNA-132, Delivered by Mesenchymal Stem Cell-Derived Exosomes, Promote Angiogenesis in Myocardial Infarction. Stem Cells International 2018, 1-11 (2018).

116. Liang, J. et al. Inhibition of microRNA-495 Enhances Therapeutic Angiogenesis of Human Induced Pluripotent Stem Cells. Stem Cells 35, 337-350, doi:10.1002/stem.2477 (2017).

117. Guohua, D., Xianbo, S., Peize, M., Ning, L. \& Jing, Y. MicroRNA-223-3p inhibits the angiogenesis of ischemic myocardial microvascular endothelial cells via modulating Rps6kb1/HIF-1 $\alpha$ signal pathway. Zhonghua Xin Xue Guan Bing Za Zhi 42, 1039-1047 (2014).

118. Song, Y., Zhang, C., Zhang, J., Jiao, Z. \& Wang, L. Localized injection of miRNA-21-enriched extracellular vesicles effectively restores cardiac function after myocardial infarction. Theranostics 9, 2346-2360 (2019).

119. Veliceasa, D. et al. Therapeutic manipulation of angiogenesis with miR-27b. Vascular Cell 7, 6, doi:10.1186/s13221-0150031-1 (2015).

120. Su, Q., Lv, X.-W., Sun, Y.-H., Ye, Z.-L. \& Qin, Z.-B. MicroRNA-494 Promotes Proliferation, Migration and Invasion of Vascular Endothelial Cells in Myocardial Infarction via Inhibiting the Wnt Signaling Pathway by Binding to LRG1. Molecular Therapy Nucleic Acids 18 (2019).

121. Song, X. W., Shan, D. K., Jian, C. \& Jing, Q. miRNAs and lncRNAs in vascular injury and remodeling. Science China 057 , 826-835 (2014).

122. Garikipati, V. N. S. et al. Circular RNA CircFndc3b modulates cardiac repair after myocardial infarction via FUS/VEGF-A axis. Nat Commun 10, 4317, doi:10.1038/s41467-019-11777-7 (2019).
This work is licensed under Creative Commons Attribution 4.0 License

To Submit Your Article Click Here: Submit Manuscript

DOI: $10.31579 / 2641-0419 / 136$

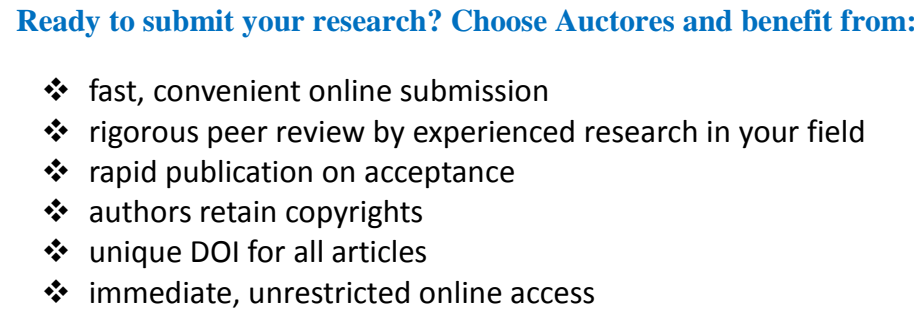

Ready to submit your research? Choose Auctores and benefit from:

- fast, convenient online submission

* rigorous peer review by experienced research in your field

* rapid publication on acceptance

* authors retain copyrights

* unique DOI for all articles

* immediate, unrestricted online access

At Auctores, research is always in progress.

Learn more www.auctoresonline.org/journals/clinical-cardiology-andcardiovascular-interventions 